\title{
Providing a liaison psychiatry service in the absence of a consultant liaison psychiatrist
}

\section{AIMS AND METHOD}

Liaison psychiatry services in Ireland are currently unequally distributed. In the absence of a specialist liaison psychiatry team, general adult psychiatrists may provide a consultation service to their local hospital. Demographic and clinical characteristics pertaining to all psychiatric consultations at the Louth County Hospital were collected over 12 months to examine one such local service and to highlight the challenges of this mode of service delivery.

\section{RESULTS}

A total of 232 consults were audited. The most frequent reasons for referral were assessment following deliberate self-harm (38\%), affective symptoms (28\%) and alcohol or substance misuse $(25 \%)$. This differs from documented referral patterns to specialist liaison teams. Referring physicians had a low diagnostic 'hit-rate' with respect to affective disorders. Difficulties in service provision included poor communication by referring teams and time constraints due to other sectoral commitments.

\section{CLINICAL IMPLICATIONS}

Refinements to service delivery may be beneficial in managing the workload more effectively. Priority should be placed on fostering communication with non-psychiatric colleagues.
The Royal College of Psychiatrists (2003) has emphasised the need for medical patients to have access to good quality psychiatric and psychological care. Liaison psychiatry services in Ireland outside of Dublin are currently poorly developed, with certain regions having little or no provision (O'Keane et al, 2005). The report of the Expert Group on Mental Health Policy (Department of Health and Children, 2006) has recommended that the number of specialist liaison teams be expanded nationally to thirteen. Furthermore, Comhairle na nOspidéal's report (2004) on consultant staffing within Irish mental health services suggested that general hospitals lacking the service of a full-time designated consultant liaison psychiatrist should have a liaison service provided by the local sectoral (general adult) psychiatry team. Delivery of a quality service in this manner is quite a challenge, since it must be provided in addition to a wide array of other sectoral responsibilities. There has been little systematic research to date examining the activity generated within such a local arrangement.

This study was undertaken at the Louth County Hospital, where a consultation-liaison service is provided on a non-emergency basis for in-patients. No cover is provided for the accident and emergency department. The service is delivered by psychiatric registrars working under the direction of sectoral general adult consultant psychiatrists. Liaison work is therefore undertaken in addition to delivery of full sectoral duties. Supervision of registrar assessments is on the basis of a consultant's or senior registrar's review of individual cases as required. Psychiatry registrars are supported by two psychiatric liaison nurses in cases where assessment is sought following episodes of deliberate self-harm.

The aims of this study were to examine the clinical characteristics of referrals to the service and to broadly compare these with data from previous studies in the Irish literature which focused on specialist liaison services, and to highlight specific challenges associated with this type of service delivery.

\section{Method}

The details of all psychiatric consultations to in-patients at Louth County Hospital were collected prospectively for a 12 -month period. In addition to demographic information, the following was recorded: source of referral, presence or absence of a referral letter, past psychiatric history including previous contact with psychiatric services, reason for referral, ICD-10 diagnosis as made by assessing psychiatrist, and suggested management or intervention.

\section{Results}

\section{Reason for referral}

A total of 242 consults were seen over the 12 -month period, of which 232 were audited. A formal letter of referral was received in $55 \%$ of cases. The most common reasons for referral were for assessment post deliberate self-harm ( $n=89,38 \%)$, assessment of affective symptoms $(n=65,28 \%)$ and alcohol or substance misuse $(n=56,25 \%)$. Remaining individuals were referred for various other reasons, including queries in relation to behavioural disturbance, confusion, pharmacotherapy, placement issues and eating disorders.

\section{Demographics}

Almost equal numbers of male and female individuals were referred for assessment (female: $n=115$; male: $n=117$ ). The age/gender distribution of the group is shown in Table 1. Of note, $22 \%$ of individuals assessed were over 65 years of age. Older individuals were 
Table 1. Age/gender distribution of individuals referred for

assessment

original

papers

\begin{tabular}{lrrr}
\hline Age (years) & Female & Male & Total \\
\hline$<20$ & 5 & 7 & 12 \\
$21-30$ & 19 & 20 & 39 \\
$31-40$ & 22 & 22 & 44 \\
$41-50$ & 15 & 24 & 39 \\
$51-60$ & 20 & 15 & 35 \\
$61-70$ & 11 & 11 & 22 \\
$71-80$ & 8 & 13 & 21 \\
$81+$ & 15 & 5 & 20 \\
Total & 115 & 117 & 232 \\
\hline
\end{tabular}

of individuals; $12.4 \%$ of individuals were diagnosed as depressed, with a further $11.2 \%$ with comorbid depression and personality disorder.

Excluding deliberate self-harm cases, there were 143 further individuals referred (Table 3, group B). Again, the most common diagnosis was harmful alcohol use or alcohol dependence syndrome (36.4\%); 18.9\% of group B had a past history of clinical depression, but had euthymia at assessment; $12.7 \%$ had acute depression; 9.8\% did not receive a formal psychiatric diagnosis. Table 4 shows interventions implemented by the assessing psychiatrist.

Table 2. Individuals presenting with deliberate self-harm (group A, $n=89$ )

Reason for self-harm

Individuals presenting with the diagnosis (\%)

Acute crisis (no formal psychiatric diagnosis)

31.4

$\begin{array}{lr}\text { Alcohol use disorder (harmful alcohol use or alcohol dependence syndrome) } & 22.4 \\ \text { Depression } & 12.4\end{array}$

Depression

Depression and personality disorder

11.2

Personality disorder

Personality disorder and alcohol use disorder

7.9

7.9

Polysubstance misuse

4.5

Other (eating disorder/psychotic illness)

\section{Table 3. Individuals with a diagnosis excluding deliberate self-harm (group $B, n=143$ )}

Diagnosis

Alcohol use disorder (harmful alcohol use or alcohol dependence syndrome)

History of depressive illness, currently euthymic

Acute depressive episode

No formal psychiatric diagnosis

Personality disorder and alcohol use disorder

Behavioural and psychological symptoms of dementia

Anxiety

Psychotic illness

Polysubstance misuse

Other
Individuals presenting with the diagnosis (\%) referred chiefly with affective symptoms or confusion / behavioural disturbance.

\section{Diagnosis}

Diagnosis is recorded in Tables 2 and 3. Individuals referred for assessment post deliberate self-harm have been grouped separately (Table 2 , group $A, n=89$ ). Almost a third of this group did not receive a formal psychiatric diagnosis and the episode of self-harm was seen as a response to acute situational factors. The most common diagnosis $(22.4 \%)$ was that of alcohol use disorder (harmful alcohol use or alcohol dependence syndrome; binge pattern drinking was not recorded as a diagnosis in this study). Comorbid personality disorder with alcohol use disorder was observed in a further $7.9 \%$

\section{Discussion}

Provision of a liaison service by the general adult team at this study location generated a considerable volume of work. Referral patterns conformed to a degree with those to specialist liaison services in the Irish literature (Freyne et al, 1992; Swanick \& Clare, 1994), with the exception of few requests for assessment of 'medically unexplained symptoms', surprisingly low numbers of individuals referred with 'confusion' or behavioural disturbance, and higher numbers of alcohol-related disorders.

Predictably, assessment following episodes of deliberate self-harm formed the bulk of clinical duties. The Louth County Hospital policy currently requires that all individuals presenting with deliberate self-harm are admitted for review by a psychiatrist, regardless of 
severity or degree of intent. However, analysis of accident and emergency records indicated that during the study period a substantial number of individuals discharged themselves directly from accident and emergency, having refused to await admission for psychiatric assessment. This is of concern, since it has been shown that individuals who discharge prior to completion of initial assessment have a considerably increased risk of repeated self-harm (Crawford \& Wessely, 1998). In 2004, the College issued a consensus statement with respect to the assessment of deliberate self-harm in accident and emergency departments and in-patient wards (Royal College of Psychiatrists, 2004). This document included the recommendation that such assessments need not necessarily be undertaken by a psychiatrist, but could equally be performed by other suitably trained professionals. It is therefore questionable as to whether it is necessary for all individuals admitted post deliberate self-harm to the Louth County Hospital to be seen by a psychiatrist, particularly given the presence of two experienced psychiatric liaison nurses. Perhaps a more useful strategy would be to have an initial psychosocial assessment completed by the liaison nurses, with subsequent assessment of the subgroup with more complex mental health problems by the junior doctor. This would greatly increase the time available for other aspects of liaison work, without compromising service quality.

The rates of alcohol use disorders among those assessed during this study were alarmingly high: $30.3 \%$ of the deliberate self-harm group $(n=27)$ and $41.4 \%$ of others $(n=59)$ were found to have an alcohol use disorder (with or without personality disorder). The adverse physical, psychological and social complications of excess acute and chronic alcohol use are well documented (Gilman \& Abraham, 2001; Babor et al, 2003; National Crime Council, 2003). Molyneux et al (2006) have demonstrated high-point prevalence of alcohol use disorders and binge drinking among in-patients in the Irish general hospital setting. Modalities such as brief intervention have been demonstrated to be clinically effective in reducing amounts of alcohol consumed in individuals with alcohol disorders (Moyer et al, 2002). At present, there is no alcohol counsellor available within the hospital to offer this type of input. Full psychiatric assessment may be neither necessary nor sufficient for many of these individuals. Single sessions with a designated alcohol counsellor with the requisite training in evidence-based brief interventions might be more helpful, in uncomplicated cases.

Several difficulties arise when a liaison service is provided by a general adult team. Perhaps the greatest challenge is the conflict created by the need to provide quality assessments in the context of significant time constraints, since sectoral duties also demand the attention of those involved. In order to provide comprehensive assessments, there is frequently the need for timeconsuming gathering of collateral history from medical staff and family. This is a challenge common to all liaison work. However, it becomes an even more pressing difficulty when assessments are performed amid a myriad other duties. Formal letters of referral were obtained from the referring medical team in only $55 \%$ of cases in this study, thereby increasing the need for information gathering by liaison team members.

Ideally, the remit of a liaison team should encompass not merely the provision of a service for psychiatric emergencies and deliberate self-harm assessments, but additionally promotion of combined approaches to mental and physical health, prevention of psychiatric morbidity and psychoeducation for non-psychiatric staff.

Time constraints, lack of a multidisciplinary team and poorly developed shared care approaches restrict the current scope of service at the Louth County Hospital. Service provision has thus become largely consultative in style. This may in turn influence referral patterns. Medical staff may incorrectly assume that the liaison service is synonymous only with deliberate self-harm assessments, since this is the most visible aspect of service provision. Direct contact between psychiatric and non-psychiatric staff is invaluable in influencing the types of individuals that are referred for assessment. At present, the majority of referrals fall predictably into a limited number of categories - deliberate self-harm, alcohol-related illness and affective-spectrum disorders. Virtually no cases of 'medically unexplained symptoms' are seen by the liaison team at the Louth County Hospital. Although this may reflect the fact that such individuals are referred initially onwards to larger centres for specialist investigations, and thence 


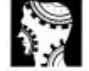

original papers to liaison services elsewhere, it may also belie a lack of recognition of psychosomatic disorders.

Liaison psychiatry demands a different set of specialised skills to those required in general adult psychiatry. The liaison psychiatrist must be adept at assessing relevant physical findings in addition to mental state, at engaging individuals with somatic presentations of psychiatric illness and at managing those with psychiatric and physical comorbidity. Such skills may not readily be learned outside of centres which have a welldeveloped specialist liaison service under consultant supervision. Nevertheless, a general adult team can do much to aid a positive attitude in the medical setting towards psychiatry, promote a bio-psychosocial approach to diagnosis, and increase the potential of physicians to treat common psychiatric disorders. Priority should be placed on fostering communication with non-psychiatric colleagues so as to optimise mutual learning.

\section{Acknowledgements}

Thanks to all members of the liaison team at Louth County Hospital.

\section{Declaration of interest}

None.

\section{References}

BABOR, T., CAETANO, R., CASSWELL, S., et al (2003) Alcohol: No Ordinary Commodity. Research and Public Policy. World Health Organization \& Oxford University Press.

COMHAIRLE NA NOSPIDÉAL (2004) Consultant Staffing in the Mental

Health Services, pp. 53-54.

Government Publications.

CRAWFORD, M. J. \& WESSELY, S. (1998) Does initial management affect rate of repetition of deliberate self-harm? BM 317, 985-990.

DEPARTMENT OF HEALTH AND CHILDREN: EXPERT GROUP ON MENTAL HEALTH POLICY (2006) A Vision for Change, pp. 154-157. Government Publications.

FREYNE, A., BUCKLEY, P., LARKIN, C., et al (1992) Consultation liaison psychiatry within the general hospital: referra pattern and management. Irish Medica Journal, 85, 112-114.

GILMAN, S. E. \& ABRAHAM, H. D. (2001) A longitudinal study of the orde of onset of alcohol dependence and major depression. Drug and Alcohol Dependence, 63, 277-286.

MOLYNEUX, G CRYAN E \& ELISA, D. (2006) The point-prevalence of alcohol use disorders and binge drinking in an Irish general hospital. Irish Journal of Psychological Medicine, 23, 17-20.

MOYER, A., FINNEY, J., SWEARINGEN $C$. et al (2002) Brief interventions for alcohol problems: a meta-analytical review of controlled investigations in treatment seeking and non-treatment seeking populations. Addiction, 97, 279-293.

NATIONAL CRIME COUNCIL (2003) Public Order Offences in Ireland. The Stationery Office Dublin.

O'KEANE, V.,WALSH, D. \& BARRY, S. 2005) Stark Facts. Irish Psychiatric Association.

ROYAL COLLEGE OF PSYCHIATRISTS (2003) The Psychological Care of

Medical Patients: A Practical Guide (CR108). Royal College of Psychiatrists ROYAL COLLEGE OF PSYCHIATRISTS (2004) Assessment Following Selfharm in Adults (CR 122). Royal College of Psychiatrists.

SWANICK, G. \& CLARE, A. (1994) Inpatient liaison psychiatry: the experience of two Irish genera hospitals without psychiatric units. Irish Journal of Psychological Medicine, 11 $123-125$

Claire Flahavan Registrar, Mater/UCD Rotational Training Scheme in Psychiatry, St James' Child Guidance Clinic, 1 James Street, Dublin 8, Ireland, email:cflahavan@ gmail.com

\section{Nurse-led liaison psychiatry service for older adults: service evaluation}

\section{AIMS AND METHOD}

To comprehensively describe a nurseled consultation liaison service for older adults by retrospectively reviewing all referrals received in 2006 and comparing them against other services and benchmark reports.

RESULTS

Of the 298 individuals referred to psychiatric services from other

\author{
hospital wards, 120 were aged $85-94$ \\ years old $(40 \%), 193$ were male $(65 \%)$ \\ and 152 were referred from geriatrics \\ (51\%). A majority of 204 have not had \\ previous contact with psychiatric \\ services (69\%). The most common \\ diagnosis was dementia (33\%, \\ $n=88$ ), with $27 \%$ individuals ( $n=65$ ) \\ being referred onwards to secondary \\ care.
}

The publication of Who Cares Wins by the Royal College of Psychiatrists (2005) has provided the best available benchmark for the service structure of liaison psychiatry for older adults. The development of specific liaison services is now a priority. Nurse-led consultation for older adult liaison services is gaining popularity. The biggest contribution of liaison nursing teams lies in planning effective discharge, continuity of care and education
(Mukaetova-Ladinska, 2006). A randomised controlled trial showed it can be effectively implemented (Baldwin et al, 2004). The efficacy is equivalent to doctor-led consultation models which may have cost-saving implications (Baldwin et al, 2004).

Who Cares Wins states that the multidisciplinary approach has advantages over the consultation method in terms of a more specialist assessment, shortened 